\title{
Common-Value Procurement Auctions with Renegotiation
}

\author{
Rimvydas Baltaduonis ${ }^{1}$, Lucas Rentschler ${ }^{2}$ \\ ${ }^{1}$ Gettysburg College, Gettysburg, USA \\ ${ }^{2}$ Universidad Fransisco Marroquín, Guatemala City, Guatemala \\ Email: rbaltadu@gettysburg.edu
}

Received 23 July 2014; revised 18 August 2014; accepted 16 September 2014

Copyright (C) 2014 by authors and Scientific Research Publishing Inc.

This work is licensed under the Creative Commons Attribution International License (CC BY).

http://creativecommons.org/licenses/by/4.0/

(c) (j) Open Access

\begin{abstract}
This note contains the equilibrium bid functions for two types of common-value procurement auctions: 1) a procurement auction in which bids represent an enforceable contract; 2) a procurement auction in which, upon learning the true cost of supplying the good, the winning bidder can renegotiate the contract with the buyer, and each bidder must submit a bond with their bid, which is returned at the end of the auction unless they are the low bidder and renegotiate the contract.
\end{abstract}

\section{Keywords}

\section{Procurement Auctions, Renegotiation, Bidding, Equilibrium}

\section{Introduction}

When a bidder in a procurement auction places a bid, she enters into a contract; if she wins the auction, she will buy the good at the price specified by the auction format. Much of the auction theory literature assumes that this contract is binding, and explores the implications of varying auction format, valuation environment, information structure, etc. Under the assumption that a bid represents a binding contract, many desirable auction properties are predicted. For instance, when bidders have independent private values, maximum efficiency is predicted and the profits of the participants are expected to be non-negative in all standard auctions (see e.g. [1]). As a result of such predictions, auctions have been increasingly trusted to allocate resources, goods and services.

However, this assumption does not always hold in practice. In many cases, there is nothing to prevent a bidder from defaulting on her promises. This might happen due to prohibitively high cost of enforcing the contract, due to laws that permit reneging on contractual promises, or the bidder may simply seek a bankruptcy protection. Furthermore, successful bidders are often able to renegotiate the terms of the contract after the auction has already occurred ([2]). If holding another auction is costly or if a delay of the contract execution is impermissible, 
the winning bidder may be able to extract additional surplus from the seller. The effect of such post-auction actions to the auction behavior is at the core of our analysis.

Empirical evidence shows that renegotiation rates may be extremely high and default rates are also non-negligible. Examples include: road construction projects and other infrastructure development. The regularity of ex post changes to bidding contracts certainly undermines the claim that auctions are a quick, efficient and transparent way to allocation problems.

In general, there are two major paths that a winning bidder can take once the auction is over: 1) honoring the auction outcome and the associated contract; or 2) engaging the seller in renegotiation of contract terms. The option of the later path increases the value of winning the auction, and in turn, may affect equilibrium bidding behavior. Only if renegotiation is accompanied by additional costs which outweigh the benefits of renegotiation will bidders ignore the opportunities to renegotiate.

In this paper, we analyze equilibrium behavior in common-value procurement auctions with conditionally independent signals. We compute closed form solutions for environments in which bids are enforceable contracts, and where winning bidders may renegotiate. In such environments we also assume that bidders must put up a bond which is returned to all bidders once the auction is over, provided that a bidder did not win the auction or renegotiate.

Procurement auctions, which may be followed by renegotiation, have been studied in the past. Reference [3] does so by assuming that bidder costs are independent and private. Reference [4] examines a common-value environment and assumes that the cost of providing the good is the sum of the two independent signals that the bidders observe. But [4] allows the winning bidder only to withdraw her bid, rather than to renegotiate. The novelty of our approach stems from the fact that we analyze equilibrium bidding in common-value environments with conditionally independent signals where both renegotiation and a forfeitable bond are modeled.

\section{Model}

A set of 2 bidders compete for the right to supply a good with a common, but uncertain cost, $C$. This cost is uniformly distributed on the interval $[\underline{c}, \bar{c}]$. Prior to placing their bids, each bidder $i \in\{1,2\}$ privately observes an estimate, $C_{i}$ of the realized value of $C$. This private signal is the true cost, $c$, plus an error term $E_{i}$, which is uniformly distributed on $[-\varepsilon, \varepsilon] . C, E_{1}$ and $E_{2}$ are independent. As such, $C_{1}$ and $C_{2}$ are conditionally independent.

After observing their signals, bidders simultaneously submit their bids. The bidder with the lowest bid wins the auction, and observes the realized cost.

\subsection{Without Renegotiation}

First consider the case in which bids represent an enforceable contract between said bidder and the buyer. Suppose there exists a symmetric and monotonically increasing bid function $\rho\left(c_{i}\right)$. Further, suppose that bidder $j$ is bidding according to this equilibrium. If bidder $i$ observes $c_{i}$, but bids as though she observes $d$, then her expected profits are

$$
\Pi_{i}\left(c_{i}, d\right)=\int_{a\left(c_{i}\right)}^{b\left(c_{i}\right)}(\rho(d)-c) F(d \mid c) f\left(c \mid c_{i}\right) \mathrm{d} c,
$$

where $a\left(c_{i}\right)=\max \left\{\underline{c}, c_{i}-\varepsilon\right\}, b\left(c_{i}\right)=\min \left\{\bar{c}, c_{i}+\varepsilon\right\}, F(d \mid c)$ is the probability of winning with a bid of $\rho(d)$ and $f\left(c \mid c_{i}\right)$ is the density function of $c$, conditional on $c_{i}$. This is

$$
\Pi_{i}\left(c_{i}, d\right)= \begin{cases}\int_{\underline{c}}^{c_{i}+\varepsilon}(\rho(d)-c)\left(1-\left(\frac{d-c+\varepsilon}{2 \varepsilon}\right)\right)\left(\frac{1}{c_{i}+\varepsilon-\underline{c}}\right) \mathrm{d} c & \text { if } c_{i} \in[\underline{c}-\varepsilon, \underline{c}+\varepsilon) \\ \int_{c_{i}-\varepsilon}^{c_{i}+\varepsilon}(\rho(d)-c)\left(1-\left(\frac{d-c+\varepsilon}{2 \varepsilon}\right)\right)\left(\frac{1}{2 \varepsilon}\right) \mathrm{d} c & \text { if } c_{i} \in[\underline{c}+\varepsilon, \bar{c}-\varepsilon) \\ \int_{c_{i}-\varepsilon}^{\bar{c}}(\rho(d)-c)\left(1-\left(\frac{d-c+\varepsilon}{2 \varepsilon}\right)\right)\left(\frac{1}{\bar{c}-c_{i}+\varepsilon}\right) \mathrm{d} c & \text { if } c_{i} \in[\bar{c}-\varepsilon, \bar{c}+\varepsilon] .\end{cases}
$$


Incentive compatibility tells us that

$$
\left.\frac{\partial \Pi_{i}\left(c_{i}, d\right)}{\partial d}\right|_{d=c_{i}}=0 .
$$

This yields a system of differential equations. Assuming continuity and $\rho(\bar{c}+\varepsilon)=\bar{c}$ gives the following solution:

$$
\rho\left(c_{i}\right)= \begin{cases}\frac{2 \underline{c}^{3}-3 \underline{c}^{2} c_{i}+c_{i}^{3}+15 \underline{c^{2}} \varepsilon-12 \underline{c} c_{i} \varepsilon-3 c_{i}^{2} \varepsilon+36 \underline{c} \varepsilon^{2}-9 c_{i} \varepsilon^{2}+35 \varepsilon^{2}-8 e^{2} \varepsilon^{3}}{3\left(\underline{c}-c_{i}+3 \varepsilon\right)^{2}} & \text { if } c_{i} \in[\underline{c}-\varepsilon, \underline{c}+\varepsilon) \\ c_{i}+\varepsilon-\left(\frac{2 \varepsilon}{3}\right) \exp \left(\frac{c_{i}+\varepsilon-\bar{c}}{\varepsilon}\right) & \text { if } c_{i} \in[\underline{c}+\varepsilon, \bar{c}-\varepsilon) \\ \frac{1}{3}\left(2 \bar{c}+c_{i}-\varepsilon\right) & \text { if } c_{i} \in[\bar{c}-\varepsilon, \bar{c}+\varepsilon] .\end{cases}
$$

Note that this bid function is monotonic, and as such the bidder with the lowest signal will always win. If, contrary to equilibrium predictions, bidders do not account for the fact that they must have the lowest signal to win the auction, then they are likely to find that they have overbid, and obtain negative profits. That is, they may fall victim to the winner's curse. Such bidding is typically observed in first-price auctions, and is the subject of a large literature ([5]). In such a scenario, winning bidders have a strong incentive to renegotiate with the buyer. Further, if such renegotiation is a possibility, this may affect bidding behavior in the auction.

\subsection{With Renegotiation and a Bond Requirement}

Now consider the case in which, after winning the auction and observing $c$, a bidder is permitted to renegotiate with the buyer. In the event of renegotiation, the winning bidder makes an offer to the buyer. The buyer can either accept or reject this offer. If she accepts, the offer is implemented. If the buyer rejects the offer, the winning bidder has a payoff of zero, and the buyer then holds another auction in which both bidders may bid and in which the realized value of $C$ is common knowledge. The buyer is assumed to have $\delta>0$ cost of delay in both of these auctions. Further, assume that bidders must put up a bond, $\mu>0$ before placing their bids. This bond is returned to bidders at the end of the auction unless they win the auction and decide not to honor their bid.

The game is solved via backwards induction. In the second auction, the unique Nash equilibrium is for both bidders to bid $c$. As such, their payoffs in this auction are zero. Next, notice that in any renegotiation between the winning bidder in the first auction and the buyer, the winning bidder will offer to supply the good for $c+\delta$, and the buyer will accept this offer. Now turning to the decision to renegotiate, notice that the winning bidder will decide to renegotiate if $b-c<\delta-\mu$ (where $b$ is the winning bid). Notice that this case is identical to the case with renegotiation if the cost of delay for the buyer was $\delta-\mu$. However, this case allows for the possibility that $\mu>\delta$. If this were the case, the buyer would gain from a renegotiated contract.

Consider the bidding decision of bidder $i$ who has observed $c_{i}$. Suppose there exists a symmetric and monotonicity increasing bid function $\zeta\left(c_{i}\right)$. Further, suppose that bidder $j$ is bidding according to this equilibrium. If bidder $i$ observes $c_{i}$, but bids as though she observes $d$, then her expected profits are

$$
\Pi_{i}\left(c_{i}, d\right)=\int_{a\left(c_{i}\right)}^{b(\zeta(d)-\delta+\mu)}(\zeta(d)-c) F(d \mid c) f\left(c \mid c_{i}\right) \mathrm{d} c,
$$

where

$$
a\left(c_{i}\right)=\max \left\{\underline{c}, c_{i}-\varepsilon\right\}, b(\zeta(d)-\delta+\mu)=\min \left\{\bar{c}, c_{i}+\varepsilon, \zeta(d)-\delta+\mu\right\},
$$

$F(d \mid c)$ is the probability of winning with a bid of $\zeta(d)$ and $f\left(c \mid c_{i}\right)$ is the density function of $c$, conditional on $c_{i}$. This is 


$$
\Pi_{i}\left(c_{i}, d\right)= \begin{cases}\int_{\underline{c}}^{b(\zeta(d)-\delta+\mu)}(\zeta(d)-c)\left(1-\left(\frac{d-c+\varepsilon}{2 \varepsilon}\right)\right)\left(\frac{1}{c_{i}+\varepsilon-\underline{c}}\right) \mathrm{d} c & \text { if } c_{i} \in[\underline{c}-\varepsilon, \underline{c}+\varepsilon) \\ \int_{c_{i}-\varepsilon}^{(\zeta(d)-\delta+\mu)}(\zeta(d)-\delta)(\beta(d)-c)\left(1-\left(\frac{d-c+\varepsilon}{2 \varepsilon}\right)\right)\left(\frac{1}{2 \varepsilon}\right) \mathrm{d} c & \text { if } c_{i} \in[\underline{c}+\varepsilon, \bar{c}-\varepsilon) \\ \int_{c_{i}-\varepsilon}^{(\zeta(d)-\delta+\mu)}(\zeta(d)-c)\left(1-\left(\frac{d-c+\varepsilon}{2 \varepsilon}\right)\right)\left(\frac{1}{\bar{c}-c_{i}+\varepsilon}\right) \mathrm{d} c & \text { if } c_{i} \in[\bar{c}-\varepsilon, \bar{c}+\varepsilon] .\end{cases}
$$

Incentive compatibility tells us that

$$
\left.\frac{\partial \Pi_{i}\left(c_{i}, d\right)}{\partial d}\right|_{d=c_{i}}=0 .
$$

This yields a system of differential equations. The solution to said system is given by

$$
\zeta\left(c_{i}\right)= \begin{cases}c_{i}+L & \text { if } c_{i} \in[\underline{c}-\varepsilon, \underline{c}+\varepsilon) \\ c_{i}+L & \text { if } c_{i} \in[\underline{c}+\varepsilon, \bar{c}-\varepsilon) \\ c_{i}+L & \text { if } c_{i} \in[\bar{c}-\varepsilon, \bar{c}+\varepsilon],\end{cases}
$$

where $L \in[-\varepsilon, \varepsilon+\delta-\mu)$. Notice that there is a continuum of symmetric and monotonically increasing equilibrium bid functions. Notice that if $\mu \geq \varepsilon+\delta+L$, then there is no incentive to renegotiate. That is, it is always possible for a buyer to ensure that the buyers will not renegotiate by choosing $\mu$ sufficiently large.

\section{Conclusions}

In this note, we have determined that if bidders have the ability to renegotiate a bidding contract in a commonvalue procurement auction with conditionally independent signals, then there exists a continuum of symmetric equilibria which are all linear in signals. However, bidders must coordinate on the particular equilibrium, which may, in practice be difficult for them to achieve. Notice that in all such equilibria the bidder with the lower signal will win the auction.

The policy recommendation from this analysis is clear. The buyer should require a substantial bond in order to ensure that renegotiation is not a profitable option for the winning bidder, in which case the analysis reverts to the case, in which the bids represent a binding contract.

An interesting extension of the current paper would be to determine whether imposing such a bond requirement would discourage entry into the auction. Can a buyer prevent renegotiation while still attracting bidders?

\section{Acknowledgements}

Many thanks to Pedro Monzon Alvarado for excellent research assistance.

\section{References}

[1] Milgrom, P.R. and Weber, R.J. (1982) A Theory of Auctions and Competitive Bidding. Econometrica, 50, $1089-1122$. http://dx.doi.org/10.2307/1911865

[2] Guasch, J.L., Laffont, J.J. and Straub, S. (2008) Renegotiation of Concession Contracts in Latin America: Evidence from the Water and Transport Sectors. International Journal of Industrial Organization, 26, 421-442. http://dx.doi.org/10.1016/j.ijindorg.2007.05.003

[3] Wang, R. (2000) Bidding and Renegotiation in Procurement Auctions. European Economic Review, 44, $1577-1597$. http://dx.doi.org/10.1016/S0014-2921(98)00082-8

[4] Roelofs, M.R. (2002) Common Value Auctions with Default: An Experimental Approach. Experimental Economics, 5, 233-252. http://dx.doi.org/10.1023/A:1020840420643

[5] Kagel, J.H. and Levin, D. (2002) Common Value Auctions and the Winner's Curse. Princeton University Press, New Jersey. 
Scientific Research Publishing (SCIRP) is one of the largest Open Access journal publishers. It is currently publishing more than 200 open access, online, peer-reviewed journals covering a wide range of academic disciplines. SCIRP serves the worldwide academic communities and contributes to the progress and application of science with its publication.

Other selected journals from SCIRP are listed as below. Submit your manuscript to us via either submit@scirp.org or Online Submission Portal.
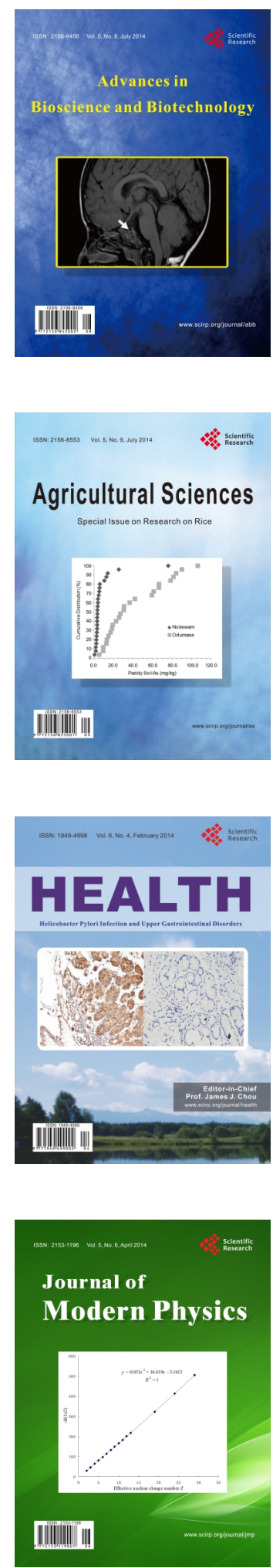
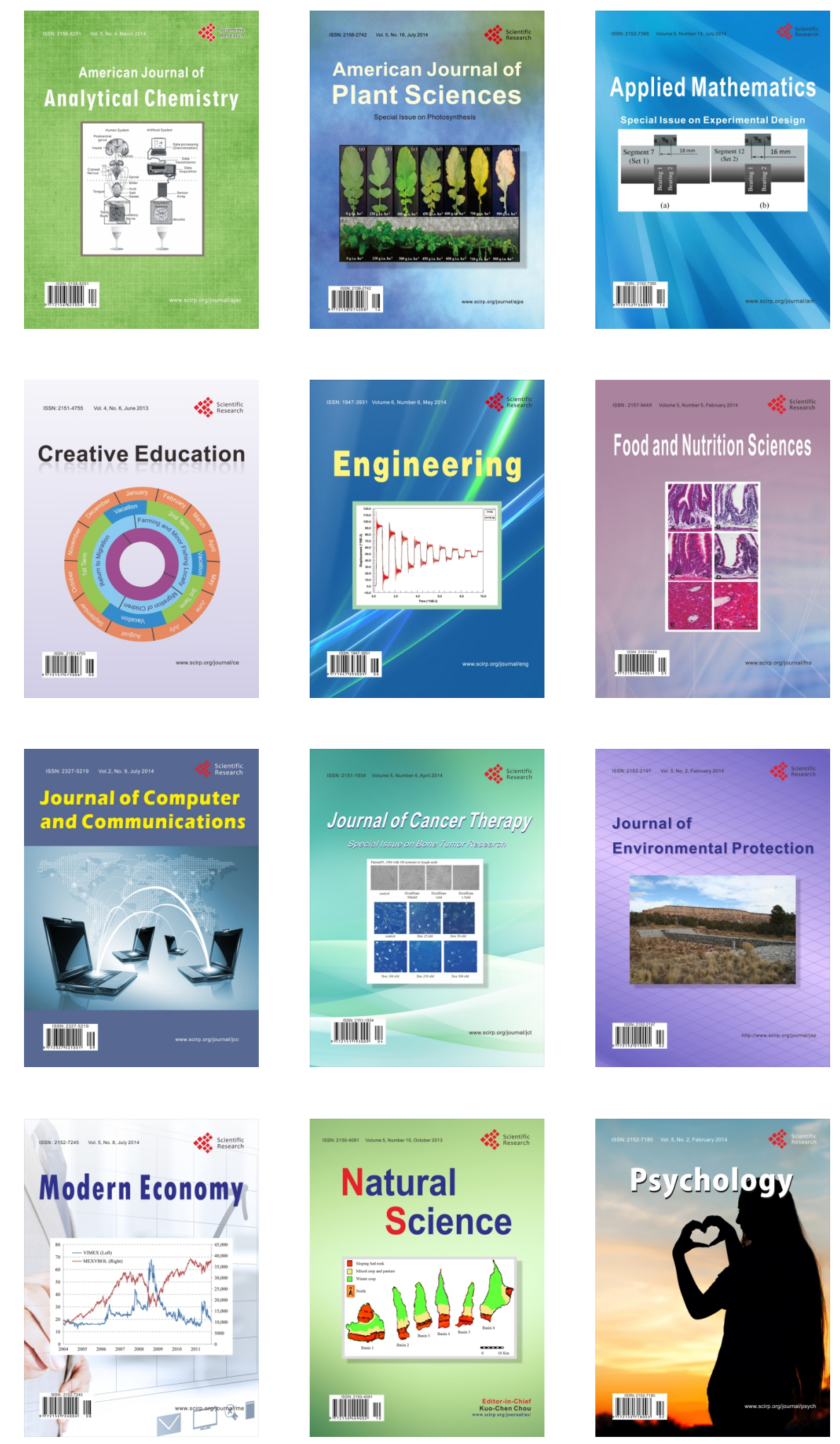